\title{
41 \\ The Need for Reform of Australia's Birth Registration Systems
}

\author{
Melissa Castan and Paula Gerber ${ }^{1}$
}

\section{Introduction}

Having a birth certificate is a key to accessing the rights of citizenship. Most Australians take it for granted that they can prove who they are by producing their birth certificate. But there are a number of Australians - predominantly Indigenous people and those from culturally and linguistically diverse (CALD) communities - who miss out on the rights and benefits of citizenship and struggle to fully participate in society because their birth has never been registered or, if it was, they cannot produce a birth certificate to prove it.

Without a birth certificate it is near impossible to obtain a driver's licence, passport or Tax File Number, or to collect your superannuation. ${ }^{2}$ But problems can start much earlier. Schools are not supposed to enrol

1 Senior Lecturer, Monash University Law Faculty, and Deputy Director of the Castan Centre for Human Rights Law (Castan); Professor, Monash University Law Faculty and Deputy Director of the Castan Centre for Human Rights Law (Gerber). This chapter arises out of research funded by the Australian Research Council pursuant to the Linkage Grant 'Closing the Gap on Indigenous Birth Registration' (LP120100160). Further resources resulting from this research can be found in Proof of Birth and in the publications set out on the project's website: www.indigenousbirthreg.org.

2 A birth certificate is known as a 'feeder' document, that is, it enables a person to obtain other forms of identification. A person may use their birth certificate to obtain a passport, which could then be used to satisfy ID requirements for other purposes such as obtaining a driver's license or opening a bank account. However, a birth certificate is invariably required to obtain the initial form of ID. 
children who do not have a birth certificate, and sports clubs will often ban kids from playing if they cannot produce a birth certificate to prove they are playing in the right age group - for example, the Under 10s soccer team or the Under $14 \mathrm{~s}$ cricket team.

Lack of a birth certificate can also be a barrier to engaging in the mainstream economy and developing financial literacy because it prevents young people from accessing the keys to economic participation, such as opening a bank account. Thus, the result of a birth not being registered is that vulnerable groups, including Indigenous children and youth, who may already suffer intergenerational disadvantage, find themselves even further behind the eight ball. They may be unable to prove who they are and therefore cannot access the rights of citizenship that most Australians take for granted. ${ }^{3}$

Indeed, not having a birth certificate can lead to a life of isolation and exclusion from society from a very early age. ${ }^{4}$ Further problems such as non-recognition as a citizen, increased risk of violence and abuse, and increased risk of separation from family during emergencies, are identified as serious issues of child protection for those whose births have not been registered. ${ }^{5}$ Around the world, it is estimated there are approximately 230 million children under five whose births have never been registered. This equates to one in every three children under five. ${ }^{6}$ Given the global scale of non-registration of births, the thousands of Australians from Indigenous and CALD communities who have not had their births registered may not seem like a significant problem. ${ }^{7}$ However, for the individuals endeavouring to negotiate life without a birth certificate, the problem is very large and very real.

3 Paula Gerber and Melissa Castan, 'The Right to Universal Birth Registration in Australia' in Melissa Castan and Paula Gerber (eds), Proof of Birth (Future Leaders, 2015), 3 (hereafter Proof of Birth). 4 See, for example, Grace Koelma, 'Australian Woman Charmaine Webster Who Legally Doesn't Exist Due to Unregistered Birth, Fights to Prove Her Identity', www.news.com.au/lifestyle/real-life/ australian-woman-charmaine-webster-who-legally-doesnt-exist-due-to-unregistered-birth-fights-toprove-her-identity/news-story/eefbd76d0451458db64c84e6fea0cc06 (viewed 7 July 2014).

5 UN High Commissioner for Refugees (UNHCR), Child Protection Issue Brief: Birth Registration, August 2013, www.refworld.org/docid/523fe9214.html (viewed 22 January 2015).

6 UNICEF, Every Child's Birth Right: Inequities and Trends in Birth Registration (2013), 14, www. unicef.org/media/files/Embargoed_11_Dec_Birth_Registration_report_low_res.pdf.

7 Will Winter 'The Minimbah Project: Facilitating Birth Registration and Certificates in Rural and Regional Communities' in Proof of Birth, 73-74. 
This chapter seeks to identify the areas where law reform will provide measurable improvements and contribute to the debate about how best to address the diverse range of issues that prevent Australia achieving truly universal birth registration.

\section{Unregistered Births in Australia}

Australia can be proud of the fact that around 96 per cent of all births are registered. ${ }^{8}$ However, the fact that the vast majority of the unregistered births come from vulnerable populations such as Indigenous and CALD communities is a cause for great concern. While the problem of nonregistration is being acknowledged and addressed in developing countries, ${ }^{9}$ there is still a reluctance to recognise that a wealthy, OECD country such as Australia has similar problems with under-registration of births within several of its minority groups.

There are two distinct, but related, factors underpinning the lack of birth certificates in Australia, namely:

1. Births are not being registered, so no certificate is available.

2. Births are registered, but a birth certificate was not obtained at the time, and cannot now be obtained because of an inability to (i) satisfy the Registrar of Births, Deaths and Marriages (BDM) ID requirements and/or (ii) pay the fees associated with acquiring a birth certificate.

There are several steps involved in registering a birth and getting a birth certificate, beginning with notification of a birth by the hospital or midwife and concluding with lodgement of a birth registration form by the parents. Notably, the statutes regulating birth registration impose significant potential penalties for late registration. ${ }^{10}$ Additionally, while registering a birth is free, applying for a birth certificate is not. A fee must be paid at the time of submitting the form. ${ }^{11}$

8 A J Lanyon and David John, 'Australia’s Civil Registration and Vital Statistics System', in Proof of Birth, 53-54.

9 UN High Commissioner for Refugees (UNHCR), Child Protection Issue Brief: Birth Registration, August 2013, www.refworld.org/docid/523fe9214.html (viewed 22 January 2015).

10 For example, in Victoria a fine of up to $\$ 1,400$ can be imposed.

11 The fees range from $\$ 31$ in Victoria and \$53 in New South Wales. Some jurisdictions, such as Victoria, have a fee relief scheme in place for Indigenous Australians. 


\section{How to Increase Birth Registration Rates within Indigenous Communities}

There are a diverse range of factors and issues that underlie non-registration of births by members of Indigenous communities. The multiplicity of causes necessitate an interdisciplinary response that incorporates legal, health, statistical, and community based approaches to the issues. Furthermore, any recommendations and reforms to birth registration, access to birth certificates and changes to identification documents should only be considered after proper consultation with, and the participation of, Indigenous communities and representative organisations. This is consistent with best practice for law reform regarding Indigenous Australians, and adheres to the Free Prior and Informed Consent standard in Art 19 of the Declaration of the Rights of Indigenous Peoples.

The majority of Australians do not experience any significant difficulty registering a birth and obtaining a birth certificate. For this reason, it cannot be said that the entire birth registration system is broken or in need of a major overall. ${ }^{12}$ Rather, as Lanyon and John suggest, what is required is 'the development and resourcing of targeted strategies to address the sub-groups of the population more likely to be at risk of not registering the birth of a child'. ${ }^{13}$

With this in mind, there are five areas where improvements could be made that would make a significant difference to how accessible and userfriendly the birth registration system is for disadvantaged sections of the community. These areas are:

\section{A. Education}

Although birth registration is recognised as a human right in international law, ${ }^{14}$ in Australia it is more often perceived as a responsibility than a right. One of the ways to increase birth registration rates in Indigenous communities would be to increase awareness of birth registration as a human right that every child has, and to highlight the benefits that flow to children from having a birth certificate.

12 Melissa Castan and Paula Gerber, 'The Way Forward' in Proof of Birth.

13 A J Lanyon and David John, 'Australia’s Civil Registration and Vital Statistics System' in Proof of Birth, 55.

14 See Art 14 of the International Covenant on Civil and Political Rights and Art 7 of the Convention on the Rights of the Child. 
The importance of birth registration to the child needs to be emphasised at a number of key life events, such as at the birth of the child, at baby health check-ups, at school enrolment, and when youths (and others) contemplate getting drivers licences.

Requiring BDM registrars to raise awareness about the importance of birth registration requires legislative reform since the current statutory regime does not include any mandate to provide public education about birth registration. ${ }^{15}$ Such legislative reform will need to be accompanied by a budget allocation that provides registrars with the funding necessary to develop and deliver educational programs and to implement more effective communication strategies.

Education about birth registration could also be usefully undertaken by federal agencies. For example, Centrelink and Medicare could help increase birth registration rates by inquiring of parents whether they have registered the child's birth, and providing tangible assistance to obtain a birth certificate, if parents have not yet obtained one. In this way, incidents of non registration could be addressed early in a child's life.

\section{B. Service delivery}

In most Australian jurisdictions, birth registration offices are based in the capital cities. Many of the communities and people who have the most difficulties accessing registration processes or certificates live in rural or remote locations, making physical access to the BDM registry facilities a significant burden.

Victoria is a notable exception. It has established approximately 25 regional Justice Centres with trained staff who are able to process applications for birth registration. The cost of running outreach programs is not insignificant. However, the success of community-led 'registration drives' 16 and other efforts to reach communities in remote regions is testament to the value of such initiatives. For example, the Department of Transport, Fines Enforcement, Births, Deaths and Marriages and Centrelink ${ }^{17}$

15 The Victorian Law Reform Commission made such a recommendation in relation to the Victorian legislation VLRC Birth registration and Birth Certificates Report (2013).

16 See Will Winters, 'The Minimbah Project: Facilitating Birth Registration and Birth Certificates in Rural and Regional Communities', Ch 6 in Proof of Birth.

17 See Alice Barter, 'Indigenous Driving Issues in the Pilbara Region', Ch 5 in Proof of Birth. 
regularly provide a 'one stop shop' for Indigenous communities in remote parts of Western Australia, and this has facilitated the registration of many births from these communities.

Another way of decentralising birth registration and certification processes is to use mobile birth registration units, and train non-registry personnel to assist in birth registration processes. Such initiatives have proven successful in Argentina, which uses mobile units to service the region of Patagonia, and Chile, which has three state-of-the-art vans fitted out with computers and satellite connections to the central registry. ${ }^{18}$

Whether the outreach programs are initiated by community groups, NGOs or government, they always require the cooperation and support of the relevant BDM registries, including making key staff available on site. In terms of law reform, then, registrars should be given specific powers, policies and resources to facilitate outreach programs, in cooperation with community groups or other government agencies, on a continuing basis. A commitment by registrars to regular outreach programs targeting communities where there is evidence of low levels of birth registration would likely see a significant improvement in birth registrations within these communities.

\section{Technology}

There are two distinct ways in which digital technologies can facilitate birth registration. The first is to increase the accessibility of the systems. At present, birth registration requires the completion of a paper application which must be submitted in person or by post. To make birth registration processes more accessible to all, there is an urgent need to move towards online processes and away from purely paper forms of birth certificate. ${ }^{19}$

There are digital birth registrations systems in place in other countries that Australian governments should be closely examining. There is much we can learn from the innovations being implemented in Uganda and other African nations making use of web-based technologies and smart

18 UNICEF, 'Birth Registration: Right from the Start' (2002) 9 Innocenti Digest 19, www.childinfo. org/files/birthregistration_Digestenglish.pdf.

19 We note, however, that in areas where there are issues of low literacy, digital technologies of themselves will only address the issues of under-registration when supported by funded caseworkers who can assist with the registration process. 
phones. ${ }^{20}$ Digital technologies make the registration and certification processes far more accessible and have led to a sharp increase in birth registration rates.

The second way that digital technologies can assist with birth registration is to enhance the exchange of information between government departments and agencies in different jurisdictions. Such sharing of information between different registry offices would have been of great assistance to Charmaine Webster, who was repeatedly directed to search the BDM registers in every state in order to establish where she was born. ${ }^{21}$ Charmaine's experience is likely to be the experience of many others who have spent years searching for a record of their birth across eight different registries around Australia.

\section{Financial assistance}

It is well known that having to pay a fee makes it more difficult for people from a low socioeconomic background to obtain a copy of their birth certificate. The fees may also operate as an unintended deterrent to birth registration, due to confusion between the (free) act of registering, and the request for certificates (which currently cost between $\$ 31$ and $\$ 53$ ). ${ }^{22}$

We concur with the view expressed by the UN Committee on the Rights of the Child that BDM registries across Australia should automatically issue the first birth certificate for free upon registration of Indigenous births. ${ }^{23}$ There are revenue implications for the registries in issuing free birth certificates. However, given that Indigenous births account for only roughly 5 per cent of all births in NSW each year, this should not represent a significant fiscal barrier. Even in the Northern Territory, where the proportion of Indigenous births is higher, the amount of revenue waived would be only a very small proportion of the registry's overall budget.

20 See Jack Regester, Ch 10 in Proof of Birth.

21 Grace Koelma, above n 4.

22 Melissa Castan and Paula Gerber, 'The Way Forward' in Proof of Birth.

23 Committee on the Rights of the Child, Concluding Observations on Australia, 28 August 2012, CRC/C/AUS/CO/4, www.ohchr.org/english/bodies/crc/docs/co/CRC_C_AUS_CO_4.pdf. 
All registries should also adopt a policy of a fee waiver for certificates, accompanied by eligibility criteria, as is the case in Victoria. Healthcare, pension and concession cardholders or others receiving Centrelink support (such as Youth Allowance or ABSTUDY) should be eligible for a fee waiver. This should be supported by a change to the relevant BDM Acts. There should also be residual discretion on the part of each registrar to waive fees on a case-by-case basis if an individual does not fall within the abovementioned groups, such as in situations of hardship. Some registrars already have such power under the relevant statute, but may not be exercising their discretion often, if at all. Registrars could consider revising their policies and procedures regarding fees for certificates, to ensure that information about fee waivers is readily accessible to all potential applicants. ${ }^{24}$

Fines and penalty provisions are also in need of reform. They are likely to be the cause of some barriers to registration of births. Many of the documents, forms and websites setting out information on birth registration warn people that failure to register a birth within the prescribed period may result in a fine. In reality such fines are rarely imposed. Registrars recognise that punishing people for registering (even when late) acts as a disincentive to others to submit late registrations. But members of the public have no way of knowing whether they will or will not be subject to a penalty, and are likely to assume that the penalty will be applied. This acts as an unintended disincentive to late registration. It is therefore recommended that all references to fines and penalties be removed from materials provided to the public. ${ }^{25}$

\section{E. Reduce reliance on birth certificate as proof of identity}

The perceived heightened risk of identity fraud has led to increased concerns regarding access to birth certificates and improper purposes for which they may be used. While this may be appropriate as a general approach, it has had significant impacts on people without birth certificates. Registrars must balance competing obligations between keeping the BDM registers secure and ensuring that all people have access to vital community services.

24 Melissa Castan and Paula Gerber, 'The Way Forward' in Proof of Birth.

25 Ibid. 
Strict identification procedures have been implemented by BDM registries and numerous other government departments and agencies, as well as private service providers (such as banks and superannuation funds). Reforms should be implemented to facilitate proof of identity without compromising the risk of fraudulent activities. ${ }^{26}$ For example, the Department of Transport in Western Australia has a 'Verification of Identity' form to assist participants living in remote areas to apply for a driver's licence where they are unable to meet the standard proof of identity requirements. This is a welcome development that other states and territories should consider. ${ }^{27}$

It would be useful for other licensing authorities and agencies to accept alternate forms of identification, for example, a certificate of Aboriginality, ${ }^{28}$ when a person cannot produce a birth certificate. ${ }^{29}$ Reducing reliance on birth certificates for proof of identity would help to increase Indigenous people's access to appropriate services and facilitate engagement with mainstream civil society.

\section{Conclusion}

This chapter has identified law and policy reform strategies that would facilitate easier access to the birth registration system by Indigenous communities and other vulnerable groups. Given the limited scope of this chapter, there are a number of aspects and issues regarding birth registration and certification that have not been addressed here. For example, it is worth considering whether the demands of the registration or certification processes themselves impact on traditional Indigenous naming practices and associated customs. Those working in law reform and advocacy for birth registration must be mindful of the historical

26 There are now Commonwealth ID guidelines that make some proof of identity processes easier, and others harder: see Commonwealth of Australia, National Identity Proofing Guidelines (Canberra, 2014), www.ag.gov.au/RightsAndProtections/IdentitySecurity/Documents/NationalIdentityProofing Guidelines.pdf. The suggestion of recognising 'alternative' identity processes is a positive development; see [5.1.3].

27 See www.transport.wa.gov.au/licensing/proof-of-identity.asp.

28 See, for example, the requirement of 'Proof of Aboriginal or Torres Strait Islander Identity' requirements for Centrelink at www.humanservices.gov.au/customer/forms/ra010, and AIATSIS 'Proof of Aboriginality' at aiatsis.gov.au/research/finding-your-family/before-you-start/proof-aboriginality.

29 See, for example, the requirements for proof of identity in order to claim superannuation: Australian Super, 'A Guide to Providing Proof of Your Identity', www.australiansuper.com/ - /media/ Files/Forms/A\%20guide\%20to\%20providing\%20proof\%20of\%20your\%20identity.ashx. 
misuse of past systems employed to identify Indigenous people, both in Australia and the rest of the world. ${ }^{30}$ When seeking to improve access to the birth registration system for Indigenous birth Australians, we must ensure that the registration processes do no harm to those they seek to aid. As already noted, it is vital that any new law and policy reform only proceed following thorough consultation with Indigenous people themselves. 
This text is taken from New Directions for Law in Australia: Essays in Contemporary Law Reform, edited by Ron Levy, Molly O’Brien, Simon Rice, Pauline Ridge and Margaret Thornton, published 2017 by ANU Press, The Australian National University, Canberra, Australia. 